\title{
Diyarbakır (Silvan, Kulp, Hazro) Yöresindeki Bazı Mahalli Armut (Pyrus communis L) Gen Kaynaklarının Belirlenmesi
}

\author{
İmameddin Oturmak ${ }^{1} \quad$ Koray Özrenk $2^{2^{*}} \quad$ Şeyda Çavuşoğlu ${ }^{3}$ \\ ${ }^{1}$ Silvan Gıda Tarım ve Hayvancılık İlçe Müdürlüğü, Silvan, Diyarbakır \\ ${ }^{2}$ Siirt Üniversitesi, Ziraat Fakültesi, Bahçe Bitkileri Bölümü, Siirt \\ ${ }^{3}$ Yüzüncü Yıl Üniversitesi, Ziraat Fakültesi, Bahçe Bitkileri Bölümü, Van
}

Geliş tarihi (Received): 15.11.2017～Kabul tarihi (Accepted): 15.12.2017

\section{Anahtar kelimeler:} Armut, pomoloji, Pyrus communis L., genotip, Diyarbakır

\section{*Sorumlu yazar}

korayozrenk@hotmail.com
Özet. Bu araştırma 2016 yılında Diyarbakırın Silvan, Kulp, Hazro ilçeleri ve bağlı köylerde yetiştirilen meyvesi kalitesi ve pazar değeri yüksek, halkın tercih ettiği mahalli armut çeşitlerinden 32 genotip üzerinde yürütülmüştür. Seçilen armut genotiplerinde fenolojik gözlemler yapılmış ve toplanan meyve örneklerinde pomolojik özellikler incelenmiştir. Fenolojik özellikler olarak tomurcuk patlaması, çiçeklenme başlangıcı, tam çiçeklenme, çiçeklenme sonu tarihi, çiçeklenme süresi ve tam çiçeklenmeden hasada kadar geçen gün sayısı (TÇHGS) ve hasat tarihi belirlenmiştir. Pomolojik özellikler yönünden incelenen çeşitlerin meyve ağırlığı 39.52-263.12 g, meyve boyu 38.03-88.77 mm, meyve eni 40.8576.97 mm, meyve sapı uzunluğu 19.87-50.10 mm, meyve sapı kalınlığı 2.45-7.98 mm, çekirdek eni 2.20-6.14 mm, çekirdek boyu 7.20-12.26 mm, meyvelerin suda çözünebilir kuru madde miktarı (SÇKM) \%10.00-24.90; titre edilebilir asitliği (TA) \%0.04-0.60; meyve suyu pH'sı 4.07-5.26 arasında değişim göstermiş̧tir. Bunun yanında mahalli armutlarda meyve kabuğu rengi, meyve eti rengi meyvelerde kumluluk ve tat durumları da belirlenmiştir. Tüm bu değerlendirmeler neticesinde tartılı derecelendirme yöntemine göre yüksek puan alan 21 HZR 01, 21 SLV 01, 21 SLV 11, 21 SLV 23, 21 SLV 13 ve 21 SLV 14 genotiplerinin diğer genotiplere göre daha üstün olduğu saptanmıştır.

\section{Determination of Some Local Pears (Pyrus communis L) Genetic Sources of Diyarbakır (Silvan, Kulp, Hazro) Region}

\section{Keywords:}

Pear, pomology, Pyrus communis L., genotype, Diyarbakır

\begin{abstract}
This research was carried out in 2016 on 32 genotypes with high fruit quality and high market value, preferred by the people grown in Diyarbakir's Silvan, Kulp, Hazro districts and affiliated villages. Phenological observations were made in selected pear genotypes and pomological characteristics were examined in collected fruit samples. The bud burst, the beginning of flowering, the full flowering, the blooming end date, the flowering time and days from full flowering to maturity (DFFM), the harvest date were determined as phenological characteristics. Pomological characteristics of fruit varieties were fruit weight 39.52-263.12 g, fruit lenght 38.03-88.77 mm, fruit width $40.85-76.97 \mathrm{~mm}$, fruit stalk length 19.87-50.10 mm, fruit stalk thickness $2.45-7.98 \mathrm{~mm}$, seed width 2.20-6.14 mm, seed lenght 7.20-12.26 mm, soluble solid content (SSC) in fruits 10.00-24.90\%; titratable acidity (TA) 0.04$0.60 \%$; fruit juice $\mathrm{pH} 4.07-5.26$. In addition to this, fruit shell color, pulp color, sandiness and flavor conditions are also determined in local pear. All of these evaluations showed that the genotypes 21 HZR 01, 21 SLV 01, 21 SLV 11, 21 SLV 23, 21 SLV 13 and 21 SLV 14 were higher than the other genotypes according to the weighed rating method.
\end{abstract}




\section{GíRiş}

Armut, ülkemizde uzun yıllardan beri yetiştiriciliği yapılan, üretim ve alan bakımından elma ile birlikte ılıman iklim meyvelerinin başında gelen bir meyve türüdür. Ancak bunların çok azı meyve kalitesi ve muhafazaya uygunluk açısından önem kazanmıştır (Bostan ve Şen 1991).

Kültüre alınan armut çeşitlerinin çoğu Pyrus communis (Avrupa armudu) ya da Pyrus serotina (Japon armudu) kökenlidir. Türkiye $P$. communis'in gen merkezleri arasında yer almaktadır. Farklı ekolojik koşullara sahip Anadolu'da her bölgeye uygun mahalli olarak yetiştirilen 600 'ü aşkın mahalli armut çeşidi bulunmaktadır (Özbek 1978). Bu armut çeşitleri çoğunlukla yazlık çeşitler olup özel veya kamu arazilerinde kendiliğinden yetişmiş Pyrus türlerine aşılanarak yetiştirilmektedir (Ünal et al., 1997).

Dünya armut üretimi 2014 yılı verilerine göre 25 798644 ton olup, Türkiye 462336 ton ile dünya üretiminde 5. sırada (\%1.8) yer almaktadır. Çin 17964 000 tonla, Arjantin 7712716 tonla, ABD 754415 tonla, İtalya 701558 tonla dünya armut üretiminde söz sahibi olan 7 başlıca ülkelerdir (FAO 2017).

Ekonomik olarak çok fazla bir değeri olmayan ve genellikle aile tüketimi ya da yerel pazarlara hitap eden mahalli çeşitler genetiksel olarak büyük bir değer arz etmektedir ve ıslah çalışmaları için bulunmaz materyallerdir. Bu nedenle mevcut armut çeşit zenginliğimiz içinden, ülkemizin değişik ekolojilerine uygun verimli ve kaliteli yerel çeşitlerin gün ısıı̆ına çıkarılması önemlidir (Bostan ve Şen 1991; Öztürk 2010).

Ülkemizin bu yerel çeşit zenginliği, meyve ıslahçılarına, damızlık materyal sağlayacak bir kaynak teşkil etmektedir. Var olan bu gen kaynaklarının korunması ve ıslah materyali olarak kullanılması, yeni değerlerin ortaya çıkarılması, bitki ıslahında çalışanların başlıca görevleri arasındadır. Verim ve kalitesi, çeşitli hastalık ve zararlılara dayanıklıı̆ı, belirli iklim ve toprak koşullarına uyabilme yeteneği yüksek olan yerel genotiplerin üstün olanlarının seçilmesi gerekmektedir (Güleryüz 1977). Ekonomik değere sahip ve genetik kaynak özelliğinde olan yerel çeşitlerimizin zamanla yok olma tehlikesiyle karşı karşıya gelmelerine firsat verilmeden, genetik materyal veya kontrollü yetiştiricilik için koruma altına alınması gereklidir (Edizer ve Güneş 1997).

2016 yılı verilerine göre Diyarbakır ili 4846 da alanda 1701 tonluk armut üretimine sahiptir. Diyarbakır'ın Silvan, Hazro ve Kulp ilçelerinde yürütülen bu çalışmanın amacl; meyvesi kaliteli ve pazar değeri yüksek, halkın tercih ettiği üstün özellikli mahalli armut genotiplerinin belirlenmesi, bunların yok olmasının önüne geçilmesi ve bazı fenolojik, pomolojik ve morfolojik özelliklerinin belirlenerek ümitvar olanların yetiştiriciliğe kazandırılmasıdır. Ayrıca araştırma bölgesindeki armut yetiştiriciliğinin mevcut durumunu, uygulanan teknik ve kültürel uygulamaları inceleyerek, karşılaşılan sorunları tespit etmek ve bu sorunlara çözüm önerileri getirmek hedeflenmektedir.

\section{MATERYAL VE METOT}

Bu araştırma, 2016 yılında Diyarbakır iline bağı Silvan, Hazro ve Kulp ilçeleri ile bunlara bağlı köylerde yürütülmüştür. Araştırma materyalini bu yörelerde uzun yıllardır yetiştiriciliği yapılan yerel armutlarının aşılı ve tohumdan yetiştirilmiş armut genotipleri oluşturmuştur. Araştırma materyalinin seçiminde öncelikle meyvesi kaliteli ve pazar değeri yüksek, halkın tercih ettiği üstün özellikli genotipler belirlenmiş ve bunlar içerisinden özellikle genotiplerin meyve ağılığı, meyve aroması ve periyodisite durumları göz önüne alınarak 'Tartılı Derecelendirmede' yapılmıştır. Araştırmada uygulanan 'Tartılı Derecelendirme Metodu' Ayfer ve Çelik (1979); Öztürk (2010) ve Şen et al., (1992)'nın önerdiği yönteme göre uygulanmıştır.

Tartılı derecelendirmede, meyvelerde incelenen özellikler, özelliklerin sınırları, özelliklerin katsayıları ve önem dereceleri Çizelge $1^{\prime}$ de verilmiştir. Her bir genotipin almış olduğu ağırlıklı toplam puan, her genotipte incelenen niteliklerin (özellik) sınıflarının puanları, rölatif puanlarla çarpılarak toplam puanı hesaplanmış ve en yüksek puanı alanlar ümitvar genotipler olarak seçilmişlerdir.

Araştırmada fenolojik, pomolojik ve morfolojik incelemeler bu konuda daha önce yapılan çalışmalar (Büyükyılmaz ve Bulagay 1983; Bostan ve Şen 1991; Ünal et al., 1997; 19 Karlıdağ ve Eşitken 2006; Öztürk 2010) dikkate alınarak yapılmıştır. 2016 yılında hasat döneminde her ağaçtan farklı yönlerden rastgele seçilen 5 adet meyve örneği alınmış ve toplanan örnekler hemen laboratuara getirilerek pomolojik özelliklerden meyve ağırlığı (g), meyve eni $(\mathrm{mm})$, meyve boyu (mm), meyve sapı uzunluğu (mm), meyve sapı kalınlığı $(\mathrm{mm})$, çekirdek sayısı (adet), çekirdek eni $(\mathrm{mm})$, çekirdek boyuna $(\mathrm{mm})$, kimyasal özelliklerden ise SÇKM (\%), pH ve titre edilebilir asitlik (\%) belirlenmiştir. Seçilen armut genotiplerine ait ağaçlarda Mart ayından itibaren belirli periyotlarla fenolojik gözlemler yapılmıştır. Fenolojik gözlem 
Oturmak ve ark., Diyarbakır (Silvan, Kulp, Hazro) Yöresindeki Bazı Mahalli Armut (Pyrus communis L) Gen Kaynaklarının Belirlenmesi

olarak; tomurcuk patlaması, çiçeklenme başlangıcı, tam çiçeklenme, çiçeklenme sonu, çiçeklenme süresi, tam çiçeklenmeden hasada kadar geçen süre (TÇHGS) ve hasat tarihleri belirlenmiştir.

Çizelge 1. Araştırmada uygulanan 'Tartılı Derecelendirme Metodu'na esas meyve özellikleri ve görece puanları.

Table 1. The main fruit characteristics and relative scores of the 'Tarded Rating Method' applied in the research.

\begin{tabular}{|c|c|c|c|c|}
\hline $\begin{array}{l}\text { Meyve kalite } \\
\text { özellikleri }\end{array}$ & $\begin{array}{r}\text { Rölatif } \\
\text { puanları }\end{array}$ & Gruplar & $\begin{array}{c}\text { Sınıf } \\
\text { aralığı }\end{array}$ & Puan \\
\hline \multirow{5}{*}{$\begin{array}{l}\text { Meyve } \\
\text { ağırlığı }\end{array}$} & \multirow{5}{*}{30} & Çok küçük & 27.33-81.91 & 1 \\
\hline & & Küçük & $81.92-136.50$ & 3 \\
\hline & & Orta & 136.51-191.09 & 5 \\
\hline & & Büyük & $191.10-245.68$ & 7 \\
\hline & & Çok Büyük & $245.69-300.27$ & 9 \\
\hline \multirow{3}{*}{ SÇKM } & \multirow{3}{*}{20} & $\mathrm{Az}$ & $8.75-10.66$ & 1 \\
\hline & & Orta & $10.67-12.58$ & 5 \\
\hline & & İyi & $12.59-14.50$ & 9 \\
\hline \multirow{3}{*}{ TEA (\%) } & \multirow{3}{*}{10} & $\mathrm{Az}$ & $0.85-1.65$ & 1 \\
\hline & & Orta & $1.66-2.46$ & 5 \\
\hline & & İyi & $2.47-3.27$ & 9 \\
\hline \multirow{3}{*}{$\begin{array}{l}\text { Çekirdek } \\
\text { sayısı }\end{array}$} & \multirow{3}{*}{15} & $\mathrm{Az}$ & $1.0-3.33$ & 9 \\
\hline & & Orta & $3.34-5.67$ & 5 \\
\hline & & Çok & $5.68-8.0$ & 1 \\
\hline \multirow{3}{*}{$\begin{array}{l}\text { Meyve } \\
\text { aroması }\end{array}$} & \multirow{3}{*}{15} & Orta & - & 1 \\
\hline & & İyi & - & 5 \\
\hline & & Çok iyi & - & 9 \\
\hline \multirow{3}{*}{ Periyodisite } & \multirow{3}{*}{10} & Göstermeyen & - & 9 \\
\hline & & $\begin{array}{l}\text { Kısmen } \\
\text { Gösteren }\end{array}$ & - & 5 \\
\hline & & Gösteren & - & 1 \\
\hline TOPLAM & 100 & & & \\
\hline
\end{tabular}

\section{BULGULAR VE TARTIŞMA}

2016 yılında Diyarbakırın Silvan, Kulp ve Hazro ilçeleri ile bunlara bağlı köylerde 32 mahalli çeşit olarak bilinen armut genotipi üzerinde yapılan gözlemler sonucunda elde edilen verilerin sonuçları Çizelge 2 ve 3'te verilmiştir.

Seleksiyon kriterleri doğrultusunda yapılan seçimlerde meyve özelliklerinden; meyve ağırlığı, meyve aroması ve periyodisiteye az meyilli olma kriterleri alınarak yapılan tartılı derecelendirmede yüksek puan alan 21 HZR 01, 21 SLV 01, 21 SLV 11, 21 SLV 23, 21 SLV 13 ve 21 SLV 14 genotiplerinin diğer genotiplere göre daha üstün olduğu saptanmıştır.

Incelenen genotiplerin ortalama meyve ağırlıkları 39.52-263.12 g arasında değişim gösterdiği ve 21 SLV 22 (Armudin) genotipi 39.52 g ile en küçük; 21 HZR 01
(Hürmiye Spi) genotipi ise $263.12 \mathrm{~g}$ ile en büyük meyveli genotip olarak belirlenmiştir.

Erzincan ovasında armutlarda sorun olan ateş yanıklığına dayanıklı genotipleri belirlemek amacıyla yapılan bir çalışmada genotiplerin meyve ağırlığının 6.23-190 g arasında değiştiği bildirilmiştir (Özrenk 2002). Ege Bölgesinde yapılan bir çalışmada ise seçilen çeşitlerin ortalama meyve ağırlıkları $21.3 \mathrm{~g}$ $337.0 \mathrm{~g}$ arasında olduğu belirlenmiştir (Ünal et al., 1997). Tokat ili merkez ilçede yürütülen bir çalışmada çeşitlerin meyve ağırlıkları 54.05 g-97.94 g arasında bulunmuştur (Edizer ve Güneş 1997). Karlıdağ ve Eşitken (2006), tarafından iki yıl süreyle yürütülen çalışmada 2000 yılında çeşitlere ait meyve ağırlıklarını 114.00 ile 211.03 g, 2001 yılında ise 101.17 ile 248.82 g, olarak tespit etmişlerdir. Polat ve Bağbozan (2014), erkenci ve yerli armut çeşitlerinde yürüttükleri çalışmada çeşitlerin meyve ağırlıklarını 21.57 ile 273.00 $\mathrm{g}$ arasında belirlemişlerdir. Diğer araştırma sonuçları ile çalışmamızda elde edilen meyve ağırlığı değerlerinin benzerlik gösterdiği kanaatine varılabilir.

Incelenen yerel armut genotiplerin meyve enleri 40.85-76.97 mm, meyve boyları 38.03-88.77 mm arasında, meyve sapı uzunlukları 19.87-50.10 mm; meyve sapı kalınlıkları ise 2.45-7.98 $\mathrm{mm}$ arasında değişmiştir. Çalışmamızda ortalama meyve boyunun 38.03 mm (21 SLV 15) ile 88.77 mm (21 HZR 01) arasında olduğu bulunmuştur. Farklı araştırıcılar tarafından yürütülen benzer çalışmalarda meyve boyları; 93.10-43.30 mm (Bostan ve Şen 1991), 54.04 mm ile 82.95 mm (Karadeniz ve Kalkışım 1996), 45.52 $\mathrm{mm}$ ile $92.32 \mathrm{~mm}$ (Edizer ve Güneş 1997), 9.52 0.50 $\mathrm{cm}$ ile $5.22 \pm 0.35 \mathrm{~cm}$ (Yarılgaç ve Yıldız 2001) arasında tespit edilmiştir. Karlıdağ ve Eşitken (2006), armut çeşitlerinin meyve ağırlıklarının yıllara göre değişim gösterdiği ve incelediği çeşitlerde meyve enini 2000 yılında 54.80 ile $77.64 \mathrm{~mm}$ arasında, 2001 yılında ise 62.50 ile $85.48 \mathrm{~mm}$ arasında belirlemişlerdir. Ayrıca yerel armut çeşitleri üzerinde yürütülen çalışmalarda meyve eninin Demirsoy et al., 2007'ye göre 39.9 mm ile $85.4 \mathrm{~mm}$ arasında, Uzun ve Karadeniz (2010)'e göre ise; $94.13 \mathrm{~mm}$ ile $35.15 \mathrm{~mm}$ arasında; Özkaplan ve Yarılgaç (2010)'a göre, 37.89-108.18 mm arasında; Polat ve Bağbozan (2014)'a göre ise, 25.91-117.33 mm olduğu belirlenmiştir. Elde ettiğimiz sonuçlar ile yukarıdaki araştırıcıların çalışmalarından elde ettikleri sonuçlarla benzerlik göstermiştir.

Çalışmamızda meyve eni 40.85 mm (21 SLV 22) ile 76.97 mm (21 HZR 01) arasında değiştiği belirlenmiştir. Armut çeşit ve genotipleri üzerilerine yürütülen çalışmalarda meyve eninin; $34.1 \mathrm{~mm}$ ile $78.5 \mathrm{~mm}$ (Bostan ve Şen 1991); $52.16 \mathrm{~mm}$ ile $72.32 \mathrm{~mm}$ 
Oturmak ve ark., Diyarbakır (Silvan, Kulp, Hazro) Yöresindeki Bazı Mahalli Armut (Pyrus communis L) Gen Kaynaklarının Belirlenmesi

Çizelge 2. İncelenen yerel armut genotiplerinin meyve ağırlığı, uzunluğu, eni, şekil indeksi, sap uzunluğu ve sap kalınlığına ait değerler.

Table2. Values of fruit weight, fruit length, fruit width, shape index, fruit stalk length and fruit stalk thickness of local pear genotypes examined.

\begin{tabular}{|c|c|c|c|c|c|c|c|}
\hline \multirow{2}{*}{$\begin{array}{c}\text { Örnek } \\
\text { no }\end{array}$} & \multirow[b]{2}{*}{ Genotipler } & \multicolumn{4}{|c|}{ Meyve } & \multirow[b]{2}{*}{$\begin{array}{c}\text { Sap uzunluğu } \\
\text { (mm) }\end{array}$} & \multirow[b]{2}{*}{$\begin{array}{c}\text { Sap kalınlığı } \\
(\mathrm{mm})\end{array}$} \\
\hline & & $\begin{array}{c}\text { Ağırlığı } \\
\text { (g) }\end{array}$ & $\begin{array}{c}\begin{array}{c}\text { Uzunluğu } \\
(\mathrm{mm})\end{array} \\
\end{array}$ & $\begin{array}{c}\text { Eni } \\
(\mathrm{mm})\end{array}$ & $\begin{array}{c}\text { Meyve şekil } \\
\text { indeksi (U/G) }\end{array}$ & & \\
\hline 1 & 21 SLV 01 & 231.24 & 69.26 & 75.10 & 0.92 & 34.36 & 5.78 \\
\hline 2 & 21 SLV 02 & 155.20 & 71.24 & 64.94 & 1.09 & 39.97 & 7.98 \\
\hline 3 & 21 HZR 01 & 263.12 & 88.77 & 76.97 & 1.15 & 50.10 & 7.80 \\
\hline 4 & 21 HZR 02 & 183.38 & 63.62 & 72.98 & 0.87 & 24.00 & 3.24 \\
\hline 5 & 21 HZR 03 & 125.06 & 60.74 & 60.36 & 1.00 & 40.08 & 4.66 \\
\hline 6 & 21 HZR 04 & 131.74 & 53.98 & 61.82 & 0.87 & 26.98 & 3.84 \\
\hline 7 & 21 SLV 03 & 118.80 & 60.92 & 51.42 & 1.18 & 41.70 & 4.13 \\
\hline 8 & 21 SLV 04 & 50.74 & 51.20 & 43.96 & 1.16 & 32.30 & 3.22 \\
\hline 9 & 21 SLV 05 & 129.98 & 60.24 & 64.66 & 0.93 & 33.40 & 3.42 \\
\hline 10 & 21 SLV 06 & 103.16 & 53.20 & 57.52 & 0.92 & 25.82 & 3.44 \\
\hline 11 & 21 SLV 07 & 123.88 & 66.06 & 59.76 & 1.10 & 41.60 & 3.82 \\
\hline 12 & 21 SLV 08 & 163.84 & 61.78 & 66.70 & 0.92 & 30.02 & 4.08 \\
\hline 13 & 21 SLV 09 & 130.88 & 66.20 & 61.16 & 1.08 & 42.80 & 4.76 \\
\hline 14 & 21 KLP 01 & 105.96 & 58.26 & 54.20 & 1.07 & 31.97 & 4.01 \\
\hline 15 & 21 KLP 02 & 98.04 & 48.22 & 56.96 & 0.84 & 30.54 & 2.98 \\
\hline 16 & 21 SLV 10 & 181.30 & 68.08 & 69.98 & 0.97 & 28.66 & 3.02 \\
\hline 17 & 21 SLV 11 & 124.20 & 66.68 & 61.12 & 1.09 & 36.54 & 3.70 \\
\hline 18 & 21 KLP 03 & 119.56 & 55.52 & 64.58 & 0.85 & 19.98 & 2.82 \\
\hline 19 & 21 SLV 12 & 61.60 & 57.68 & 47.24 & 1.22 & 29.78 & 4.26 \\
\hline 20 & 21 SLV 13 & 182.98 & 61.02 & 69.52 & 0.87 & 45.34 & 4.08 \\
\hline 21 & 21 SLV 14 & 112.90 & 51.70 & 61.02 & 0.84 & 19.87 & 3.64 \\
\hline 22 & 21 SLV 15 & 41.68 & 38.03 & 43.02 & 0.88 & 29.02 & 3.30 \\
\hline 23 & 21 SLV 16 & 113.56 & 54.04 & 65.11 & 0.82 & 22.00 & 2.75 \\
\hline 24 & 21 SLV 17 & 99.40 & 57.72 & 56.60 & 1.01 & 28.10 & 2.75 \\
\hline 25 & $21 \mathrm{HZR} 05$ & 115.54 & 56.44 & 66.62 & 0.84 & 33.91 & 2.45 \\
\hline 26 & 21 SLV 18 & 174.01 & 52.70 & 68.51 & 0.76 & 23.48 & 3.34 \\
\hline 27 & 21 SLV 19 & 98.22 & 58.38 & 61.13 & 0.95 & 29.01 & 2.58 \\
\hline 28 & 21 SLV 20 & 77.68 & 58.00 & 49.05 & 1.18 & 46.00 & 2.78 \\
\hline 29 & 21 SLV 21 & 127.60 & 78.17 & 66.62 & 1.17 & 47.31 & 2.95 \\
\hline 30 & 21 SLV 22 & 39.52 & 47.85 & 40.85 & 1.17 & 31.51 & 2.56 \\
\hline 31 & 21 SLV 23 & 174.58 & 82.10 & 68.74 & 1.19 & 49.57 & 3.34 \\
\hline 32 & 21 SLV 24 & 48.18 & 42.83 & 48.71 & 0.87 & 32.45 & 2.75 \\
\hline
\end{tabular}

(Karadeniz ve Kalkışım 1996); 45.52 mm ile $92.32 \mathrm{~mm}$ (Edizer ve Güneş 1997); $90.0 \pm 4.5 \mathrm{~mm}$ ile $57.4 \pm 2.2 \mathrm{~mm}$ (Yarılgaç ve Yıldız 2001); $41.9 \mathrm{~mm}$ ile $80.3 \mathrm{~mm}$ (Demirsoy et al., 2007); 41.82-68.85 mm (Uzun ve Karadeniz 2010); 31.36 - 72.97 mm, (Özkaplan ve Yarılgaç 2010); 53.07-112.93 mm, (Öztürk ve Demirsoy 2010); ve 34.1-82.0 mm (Bostan ve Acar 2012) arasında tespit edilmiştir. Bu değerler ile incelenen armut genotiplerinden elde edilen değerler paralellik göstermektedir.

Çalışmada armut genotiplerinin suda çözünür kuru madde miktarı (SÇKM) \%10.00 (21 SLV 04) ile \%24.90 (21 SLV 22) arasında değişmiştir. Bostan ve Şen (1991)'e göre, \%9-16.2; Karadeniz ve Kalkışım (1996)'a göre, \%10.60-14.10; Edizer ve Güneş (1997)'e göre, \%10.88-15.44; Yarılgaç ve Yıldız (2001)'a göre, \%17.009.80; Özrenk (2002)'e göre ise \%7-16.6; Demirsoy et al., (2007)'a göre, \%9-15.1; Uzun ve Karadeniz (2010)'e göre, \%18-8.5; Özkaplan ve Yarılgaç (2010)'a göre, \%7.0-16.25; Öztürk ve Demirsoy (2010)'a göre, \%11.016.2; Çiftçi et al., (2011)'a göre, \%7.0-19.7; arasında olduğu diğer araştırıcılar tarafından bildirilmiştir. Elde edilen sonuçlara bakıldığında SÇKM oranlarının diğer araştırmaların sonuçlarına göre yüksek çıktığı görülmektedir. Bu durum yörenin özellikle yaz aylarında çok sıcak geçmesi sonucunda genotiplerin su kaybının fazla olduğu şeklinde yorumlanabilir.

Çalışmadaki pH değeri en düşük genotip 21 SLV 12 (4.07) olurken, (21 HZR 03) 5.26 en yüksek genotip Bostan ve Şen (1991)'e göre, 3.35-5.18; Karadeniz ve Kalkışım (1996)'a göre, 3.15-4.62; Özrenk (2002)'e göre, 3.20-5.7; Uzun ve Karadeniz (2010)'e göre, 3.735.8; Özkaplan ve Yarılgaç (2010)'a göre, 3.80-6.25; Bostan ve Acar (2012)'a göre, 0.6-3.3 arasında 
Oturmak ve ark., Diyarbakır (Silvan, Kulp, Hazro) Yöresindeki Bazı Mahalli Armut (Pyrus communis L) Gen Kaynaklarının Belirlenmesi

değiştiği belirlenmiştir. Incelenen armut genotiplerinin $\mathrm{pH}$ içerikleri diğer araştırıcıların armut çeşit ve genotiplerinin $\mathrm{pH}$ içerikleri ile karşılaştırıldığında sonuçların çok farklı olmadığı görülmektedir.

Araştırmada incelenen genotiplerde titre edilebilir asit miktarının en düşük 21 SLV 22 ve 21 SLV 23 genotiplerinde (\%0.04); en yüksek ise 21 SLV 13genotipinde (\%0.60) olduğu belirlenmiştir. Yapılan benzer çalışmalarda titre edilebilir asit miktarının Karadeniz ve Kalkışım (1996)'a göre, \%0.097-\%0.258; Yarılgaç ve Yıldız (2001)'a göre, \%0.240-\%2.451; Özrenk (2002)'e göre, \%0.09-0.63 Demirsoy et al., (2007)'e göre, \%0.12-\%0.52; Uzun ve Karadeniz (2010)'e göre, \%0.07-0.60; Özkaplan ve Yarılgaç (2010)'a göre, \%0.07-0.66; Öztürk ve Demirsoy (2013)'a göre, \%0.13-1.02; Çiftçi et al., (2011)'a göre,
\%0.04-0.72; Bostan ve Acar (2012)'a göre, \%4.6-5.7; Polat ve Bağbozan (2014)'a göre ise, \%0.10-\%0.94 arasında olduğu belirlenmiştir. Elde edilen sonuçlar diğer araştırıcıların sonuçları ile benzerlik göstermektedir.

Diyarabakır'ın bu üç ilçesinde yapılan gözlemler doğrultusunda; çalışma alanlarında armut yetiştiriciliğinin kapama bahçeler halinde değil, dağınık halde, tarla ve yol kenarlarında tohumdan çıkmış ya da yabani armutlara aşılanmış ağaçlardan oluştuğu tespit edilmiştir. Bu yetiştiricilik tarzı hastalık etmenlerinin ortaya çıkmasını ve yayılımını kolaylaştıracaktır. Ayrıca armut ağaçlarında yeterince bakım işlemlerinin yapılmadığı ve hastalıkların yayılmasını ve zararını önleyebilecek kültürel önlemlerin (budama, yabancı ot mücadelesi, kurumuş

Çizelge 3. Incelenen yerel armut genotiplerine ait meyve ve çekirdeklerin fiziksel ve kimyasal değerleri.

Table 3. Physical and chemical values of fruit and kernel of local pear genotypes observed.

\begin{tabular}{|c|c|c|c|c|c|c|c|c|}
\hline \multirow[b]{2}{*}{$\begin{array}{c}\text { Örnek } \\
\text { no }\end{array}$} & \multirow[b]{2}{*}{ Genotipler } & \multirow[b]{2}{*}{$\begin{array}{c}\text { SÇKM } \\
(\%)\end{array}$} & \multirow[b]{2}{*}{$\begin{array}{c}\text { TEA miktarı } \\
\text { (\%) }\end{array}$} & \multirow[b]{2}{*}{ pH } & \multirow{2}{*}{$\begin{array}{c}\text { Çekirdek } \\
\text { sayısı } \\
\text { (Adet) }\end{array}$} & \multicolumn{3}{|c|}{ Çekirdek } \\
\hline & & & & & & $\begin{array}{l}\text { Ağırlığı } \\
\text { (g) }\end{array}$ & $\begin{array}{l}\text { Uzunluğu } \\
\text { (mm) }\end{array}$ & $\begin{array}{c}\text { Eni } \\
(\mathrm{mm})\end{array}$ \\
\hline 1 & 21 SLV 01 & 15.2 & 0.14 & 5.25 & 3.0 & 0.18 & 7.86 & 3.23 \\
\hline 2 & 21SLV 02 & 12.5 & 0.12 & 5.07 & 5.0 & 0.38 & 11.14 & 5.88 \\
\hline 3 & 21 HZR 01 & 13.2 & 0.09 & 5.06 & 3.0 & 0.74 & 12.26 & 4.98 \\
\hline 4 & 21 HZR 02 & 12.2 & 0.30 & 4.30 & 4.0 & 0.72 & 10.39 & 5.44 \\
\hline 5 & 21 HZR 03 & 18.8 & 0.15 & 5.26 & 7.0 & 0.67 & 9.32 & 3.51 \\
\hline 6 & 21 HZR 04 & 15.0 & 0.23 & 4.29 & 4.0 & 0.95 & 10.63 & 5.37 \\
\hline 7 & 21 SLV 03 & 11.2 & 0.13 & 5.25 & 1.0 & 0.31 & 11.05 & 5.38 \\
\hline 8 & 21 SLV 04 & 10.0 & 0.28 & 4.30 & 4.0 & 0.30 & 8.70 & 4.30 \\
\hline 9 & 21 SLV 05 & 11.0 & 0.10 & 5.13 & 5.0 & 0.61 & 8.13 & 3.53 \\
\hline 10 & 21 SLV 06 & 18.0 & 0.15 & 4.11 & 3.0 & 0.29 & 8.80 & 3.86 \\
\hline 11 & 21 SLV 07 & 12.9 & 0.11 & 4.82 & 4.0 & 0.51 & 7.98 & 3.40 \\
\hline 12 & 21 SLV 08 & 13.5 & 0.16 & 4.26 & 5.0 & 0.32 & 7.20 & 2.20 \\
\hline 13 & 21 SLV 09 & 12.0 & 0.11 & 5.07 & 5.0 & 0.70 & 8.50 & 4.26 \\
\hline 14 & 21 KLP 01 & 14.5 & 0.09 & 4.93 & 6.0 & 0.69 & 8.40 & 4.06 \\
\hline 15 & 21 KLP 02 & 14.5 & 0.21 & 4.58 & 6.0 & 0.51 & 8.43 & 4.30 \\
\hline 16 & 21 SLV 10 & 12.9 & 0.18 & 4.37 & 5.0 & 0.17 & 10.83 & 4.50 \\
\hline 17 & 21 SLV 11 & 13.3 & 0.13 & 4.79 & 3.0 & 0.43 & 11.72 & 5.05 \\
\hline 18 & 21 KLP 03 & 14.1 & 0.23 & 4.74 & 4.0 & 0.44 & 8.83 & 5.06 \\
\hline 19 & 21 SLV 12 & 12.8 & 0.18 & 4.07 & 5.0 & 0.34 & 7.95 & 4.67 \\
\hline 20 & 21 SLV 13 & 19.1 & 0.60 & 4.13 & 2.0 & 0.21 & 7.50 & 3.80 \\
\hline 21 & 21 SLV 14 & 15.5 & 0.23 & 4.80 & 3.0 & 0.73 & 8.40 & 5.23 \\
\hline 22 & 21 SLV 15 & 11.7 & 0.12 & 4.56 & 3.0 & 1.06 & 9.42 & 6.14 \\
\hline 23 & 21 SLV 16 & 20.1 & 0.06 & 4.62 & 6.0 & 0.57 & 9.04 & 4.29 \\
\hline 24 & 21 SLV 17 & 20.8 & 0.09 & 4.37 & 8.0 & 0.63 & 9.51 & 4.46 \\
\hline 25 & 21 HZR 05 & 16.1 & 0.07 & 4.79 & 5.0 & 0.46 & 8.49 & 4.69 \\
\hline 26 & 21 SLV 18 & 11.2 & 0.09 & 4.39 & 7.0 & 0.69 & 9.91 & 5.23 \\
\hline 27 & 21 SLV 19 & 19.8 & 0.08 & 4.44 & 5.0 & 0.82 & 9.58 & 5.57 \\
\hline 28 & 21 SLV 20 & 19.2 & 0.06 & 5.10 & 8.0 & 0.67 & 10.91 & 4.74 \\
\hline 29 & 21 SLV 21 & 17.0 & 0.11 & 4.26 & 4.0 & 0.44 & 8.02 & 4.20 \\
\hline 30 & 21 SLV 22 & 24.9 & 0.04 & 5.23 & 4.0 & 0.40 & 9.00 & 4.28 \\
\hline 31 & 21 SLV 23 & 17.1 & 0.04 & 5.11 & 2.0 & 0.59 & 11.01 & 4.61 \\
\hline 32 & 21 SLV 24 & 20.1 & 0.06 & 4.58 & 6.0 & 0.38 & 9.71 & 4.56 \\
\hline
\end{tabular}


Oturmak ve ark., Diyarbakır (Silvan, Kulp, Hazro) Yöresindeki Bazı Mahalli Armut (Pyrus communis L) Gen Kaynaklarının Belirlenmesi

dalların ve sürgünlerin kesilmesi vb.) yeterli ölçüde ve zamanında yapılmadığı saptanmıştır.

\section{SONUÇ}

Diyarbakır'ın Silvan, Kulp ve Hazro ilçelerinde yetiştiriciliği yapılan ve araştırma materyali olarak ele alınan mahalli armut genotiplerinde yapılan değerlendirmeler sonucunda, seleksiyon kriterleri doğrultusunda yapılan seçimlerde meyve özelliklerinden; meyve ağırlığı, meyve aroması ve periyodisiteye az meyilli olma kriterleri alınarak yapılan tartılı derecelendirmede yüksek puan alan 21 HZR 01, 21 SLV 01, 21 SLV 11, 21 SLV 23, 21 SLV 13 ve 21 SLV 14 genotiplerinin diğer genotiplere göre daha üstün olduğu saptanmıştır.

Yörede en erken olgunlaşan ancak depolamaya dayanıklı olmayan yöresel ismiyle bilinen Cezere (21 SLV 12) yerel pazarlarda ilk satışa sunulan genotiptir. En son hasat edilen tip ise yerel ismiyle Şekok olarak bilinen (21 SLV 24) genotipidir. Yörede yaz mevsimi sonunda olgunlaşmaya başlayıp sonbaharın sonuna kadar yerel pazarlarda bulunabilen, depolamaya orta derece dayanıklı yöresel ismi Payize olan (21 SLV 08) genotiptir.

Söz konusu genotiplerin yerel pazarda alıcı bulduğu ve diğerlerine göre üstün özelliklere sahip olması önemli gen kaynaklarının tespiti, korunması ve ileri çalışmalara kaynak oluşturması yanında yapılacak ıslah çalışmalarında gen kaynağı olarak kullanılabileceği düşünülmektedir.

\section{KAYNAKLAR}

Ayfer M and M Celik., 1979. A study on compatibility of Akça, Ankara and Williams pear cultivars with S.Ö. quince rootstock. TUBITAK VI. Scientific Congress, Horticulture, 84: 111-112.

Bostan SZ ve Şen SM., 1991. Van ve çevresinde yetiştirilen mahalli armut çeşitlerinin morfolojik ve pomolojik özellikleri üzerinde araştırmalar. Yüzüncü Yıl Üniversitesi Ziraat Fakültesi Dergisi, 1: 1-3.

Bostan SZ ve Acar S., 2012. Ünye'de (Ordu) yetiştirilen yerel armut çeşitlerinin pomolojik özellikleri. Akademik Ziraat Dergisi, 1(2): 97-106.

Büyükyılmaz M ve Bulagay AN., 1983. Marmara Bölgesi için ümitvar armut çeşitleri-II. Bahçe, 12(2): 5-14.

Çiftçi DT., Sağır N., Bağcı MD ve Aygün A., 2011. Doğu Karadeniz Bölgesi'nde Yetiştirilen Yerel Armut (Pyrus Spp.) Çeşitlerinin Bazı Özelliklerinin Belirlenmesi. Türkiye VI. Ulusal Bahçe Bitkileri Kongresi, Harran Üniversitesi Ziraat Fakültesi, 4-8 Ekim 2011, Şanlıurfa.

Demirsoy L., Öztürk A., Serdar Ü ve Duman E., 2007. Saklı Cennet Camili'de Yetiştirilen Yerel Armut Çeşitleri.
Türkiye V. Ulusal Bahçe Bitkileri Kongresi, Atatürk Üniversitesi Ziraat Fakültesi, 04-07 Eylül 2007, Erzurum.

Edizer Y ve Güneş M.,1997. Tokat Yöresinde Yetiştirilen Yerel Elma ve Armut Çeşitlerinin Bazı Pomolojik Özellikleri Üzerine Bir Araştırma. Yumuşak Çekirdekli Meyveler Sempozyumu, Atatürk Bahçe Kültürleri Araştırma Enstitüsü, 2-5 Eylül 1997, Yalova.

FAO 2017. Production statistics. http://www.fao.org/ faostat/en/\#data/QC. [Access: December 01, 2017].

Güleryüz M., 1977. Erzincan'da Yetiştirilen Bazı Önemli Elma ve Armut Çeşitlerinin Pomolojileri ve Döllenme Biyolojileri Üzerine Bir Araştırma. Atatürk Üniversitesi Yayınevi, No:229, Erzurum.

Karadeniz T ve Kalkışım Ö., 1996. Görele ve çevresinde yetiştirilen mahalli yazlık armut çeşitleri üzerinde pomolojik çalışmalar. Yüzüncü Yıl Üniversitesi Ziraat Fakültesi Dergisi 6(1): 81-86.

Karlıdağ $H$ ve Eşitken A., 2006. Yukarı Çoruh vadisinde yetiştirilen elma ve armut çeşitlerinin bazı pomolojik özelliklerinin belirlenmesi. Yüzüncü Yıl Üniversitesi Tarım Bilimleri Dergisi, 16(2): 93-96.

Özbek S., 1978. Özel Meyvecilik. Çukurova Üniversitesi Yayınları, Yayın No: 128, Adana.

Özkaplan M ve Yarılgaç T., 2010. Ordu ve çevresinde yetişen yerel armut çeşitlerinin (Pyrus communis L.) fenolojik ve pomolojik özellikleri. Yüksek Lisans Tezi (Basılmamış). Yüzüncü Yıl Üniversitesi Fen Bilimleri Enstitüsü, Van.

Özrenk K., 2002. Erzincan ovasında armutlarda sorun olan ateş yanıklığı hastalığı (Erwinia amylovora (Burill) Winslow et al.)'na dayanıklı genotiplerin belirlenmesi. Doktora Tezi (Basılmamış), Yüzüncü Yıl Üniversitesi Fen Bilimleri Enstitüsü, Van.

Öztürk A., 2010. Sinop ilindeki armut genotiplerinin morfolojik, pomolojik ve moleküler karakterizasyonu üzerine bir çalışma. Doktora Tezi (Basılmamış), Ondokuz Mayıs Üniversitesi Fen Bilimleri Enstitüsü, Samsun.

Öztürk A and Demirsoy L., 2013. Promising pear genotypes from North Anatolia, Turkey: 31 preliminary observations. Journal of the American Pomological Society, 67(4): 217-227.

Polat M ve Bağbozan R., 2014. Eğirdir (Isparta) ekolojisinde yetiştirilen erkenci yerli armut (Pyrus communis L.) tiplerinin bazı meyve özelliklerinin belirlenmesi. Süleyman Demirel Üniversitesi Fen Bilimleri Enstitüsü Dergisi. 21(1): 9-12.

Şen SM., Cangi R., Bostan SZ., Balta F ve Karadeniz T., 1992. Van ve çevresinde yetiştirilen seçilmiş bazı Mellaki ve Ankara armut çeşitlerinin fenolojik, morfolojik ve pomolojik özellikleri üzerinde araştırmalar. Yüzüncü Yıl Üniversitesi Ziraat Fakültesi Dergisi, 2(2): 29-40.

Uzun IT ve Karadeniz T., 2010. Akoluk ve Özdil beldelerinde (Trabzon) yetiştirilen mahalli armut çeşit ve tiplerinin 
Oturmak ve ark., Diyarbakır (Silvan, Kulp, Hazro) Yöresindeki Bazı Mahalli Armut (Pyrus communis L) Gen Kaynaklarının Belirlenmesi

pomolojik, fenolojik ve morfolojik özellikleri. Yüksek Lisans Tezi (Basılmamış), Ordu Üniversitesi Fen Bilimleri Enstitüsü, Ordu.

Ünal A., Saygılı H., Hepaksoy S., Can HZ ve Türküsay H., 1997. Ege Bölgesinde Armut Yetiştiriciliği ve Seçilen Bazı Armut Çeşitlerinin Pomolojik Özellikleri. Yumuşak Çekirdekli Meyveler Sempozyumu, Atatürk Bahçe Kültürleri
Araştırma Enstitüsü, 2-5 Eylül, Yalova.

Yarılgaç T ve Yıldız K., 2001. Adilcevaz ilçesinde yetiştirilen mahalli armut çeşitlerinin bazı pomolojik özellikleri. Yüzüncü Yıl Üniversitesi Ziraat Fakültesi Dergisi, 11(2): 9 12. 